\title{
IMPLEMENTATION AND ACCEPTANCE OF ONLINE LEARNING IN THE INDONESIAN CIVIL SERVICE: ARE WE THERE YET?
}

\author{
Fairman $\mathrm{B}^{1 *}$, Salak $\mathrm{AM}^{2}$, Maliki $\mathrm{MA}^{3}$, and Voak $\mathrm{A}^{4}$ \\ ${ }^{1}$ ASEAN Institute of Applied Learning, Jakarta, Indonesia \\ ${ }^{2}$ The National Institute of Public Administration-NIPA, Jakarta, Indonesia \\ ${ }^{3}$ NIPA Jakarta, Indonesia \\ ${ }^{4}$ James Cook University, Cairns, Australia
}

\begin{abstract}
COVID-19 is just the latest of a series of disruptions to the world's economic order. Even before the pandemic, business models were being transformed by the demands of globalization, urbanization and disruptive technologies. As a consequence, almost every aspect of our lives is undergoing rapid change at an unprecedented pace. COVID-19 has modified not only the way we work, but also how workforces learn, collaborate and communicate. The pandemic has also seen a rapid movement to e-learning interventions, resulting in a rebalancing of power relationships between teacher and learner. However, an e-learning environment requires learners to take a more active role in their own learning, and as a result, as learners seek out greater active participation and engagement, they play a more significant role in the learning process (Seta et al., 2020). An outcome of this change is that within human capability programs in Indonesia, the 'Teacher-centred' style of presentation is losing cultural relevance, and there is a dynamic movement towards a more 'Student-centred' approach. The implications of this development are that trainers need to perform new, more non-traditional roles as mentors, coaches and learner guides (Fairman et al., 2020). To meet the requirements of these changes, there is a need to urgently reconsider the relevance of classical teaching approaches in Indonesia. This paper examines the learning and development programs as implemented by the National Institute of Public Administration (NIPA), which is largely responsible for building human resource capability across the Indonesian civil service (Murti, 2020). During the COVID pandemic, NIPA has moved from their 'classical' forms of training towards 'online learning', and the impact of this 'shift' has raised a number of challenges for NIPA staff and the role they play in developing Indonesia’s human capital.
\end{abstract}

Keywords: human capability development, applied learning, skills development, COVID19

\section{Introduction}

It has been widely observed, and existing trends indicate that, the requirements for handling Covid-19 have accelerated the acceptance of e-learning across the globe. As communities have experienced prolonged lockdowns, traditional 'face-to-face' learning has been superseded by 'online' learning, creating issues such as the replacement of traditional learning with a somewhat untested, yet reliable, learning channel for educational delivery. However, long before the pandemic, human capital development was being constantly reshaped in response to rapid technological change. Since this alteration to work life in many areas of endeavour does not look like abating, organizations and employees are now continually faced with new re-skilling challenges. 
With respect to learning programs, there are number of important contributions of this change relating to the learner and teacher relationship, including a significant shift towards student-centred and lifelong learning. It is becoming evident that a learner who is committed to lifelong learning will have significant advantages when adapting to rapid technological advancement and when dealing with its direct impact on the work environment. Additionally, career modification, career adjustment and changes in employment relationships all mean that individuals will need to take a more active role in accessing and developing new skills in order to adapt to ever-renewing workplace practices (Fairman et al., 2020).

This paper examines the human capability challenges experienced by the National Institute of Public Administration (NIPA) as a result of the pandemic. The NIPA, which is responsible for building human resource capability across the Indonesian Civil Service (Murti, 2020), have modified their 'classical' face-to-face forms of training toward 'e-learning', for both their pre-service and in-service staff. Of importance is that the impact of this pedagogical shift has raised a number of questions for NIPA staff and the Indonesian civil service as they move into the post-pandemic era, particularly in regard to how e-learning is to be integrated into future capability development interventions across the Archipelago. Further, administrative management and learning support systems will need to reflect the needs of more information technology-focused organizations (Kardinasari, 2015), and it is the objective of this paper to examine these challenges.

In examining the impact of 'online' learning, we recognize that participatory education requires more from the learner in the form of engaging with the learning tasks. The development of a personal style of learning which will provide a structure and foundation for life-long learning is essential for this development. However, (Siron et al., 2020) noted that in the Indonesian educational context, the implementation of e-learning and life-long learning are constrained by some enormous challenges in areas such as: (i) insufficient internet accessibility, (ii) technical skills, (iii) administration support, and (iv) inadequate content design. It has been commented that Indonesian students urgently require added skills in adaptability when using e-learning platforms, and e-learning environments need to be interactive, to provide learner feedback as well as learner control, and to include learner response options (Kaunang \& Usagawa, 2017).

\section{Methodology}

NIPA was concerned about the perceived impact of the shift away from traditional 'classical' training toward 'online learning' and, in consequence, instigated a survey of over 100 NIPA recipients of their training. A survey questionnaire of 30 questions seeking training recipients' responses to the changes in teaching methodology was developed in order to ascertain (i) their experiences with on-line learning from home and work, (ii) their understandings of the benefits and challenges inherent in online learning, and (iii) their suggestions for possible improvements in online learning for the future. Demographic data around 'length of service', 'age', 'years in employment', 'place of employment' and 'job title' was collected to allow closer analysis of the responses. This was followed up with targeted and selected interviews which were designed to seek more detailed understanding related to key concerns emerging from the survey.

NIPA training activities are developed on the basis of the central and pivotal role played by the Indonesian Civil Service in meeting service outcomes for the Indonesian population. They are 
therefore appropriate for Civil Service personnel, and for this evaluation, respondents were drawn from 'central' and 'provincial' ministries, as well as pre-service staff wanting to become Indonesian civil servants to provide a non-biased set of responses. Given that it is widely agreed that building human capability across Indonesia is a critical factor in providing services to the third-largest democracy in the world (Kardinasari et al., 2019), the imparting of skills, knowledge and attitudes is of fundamental importance to the country, and it is noted that the most popular civil service job type is that of a teacher (trainer) (Sacks \& Pierskalla, 2018). The respondents to our survey consisted of Training staff, Pre-service staff, Policy Analysts, Lecturers and Managers. The following graph (Figure 1) illustrates the percentage breakdown of these respondents:

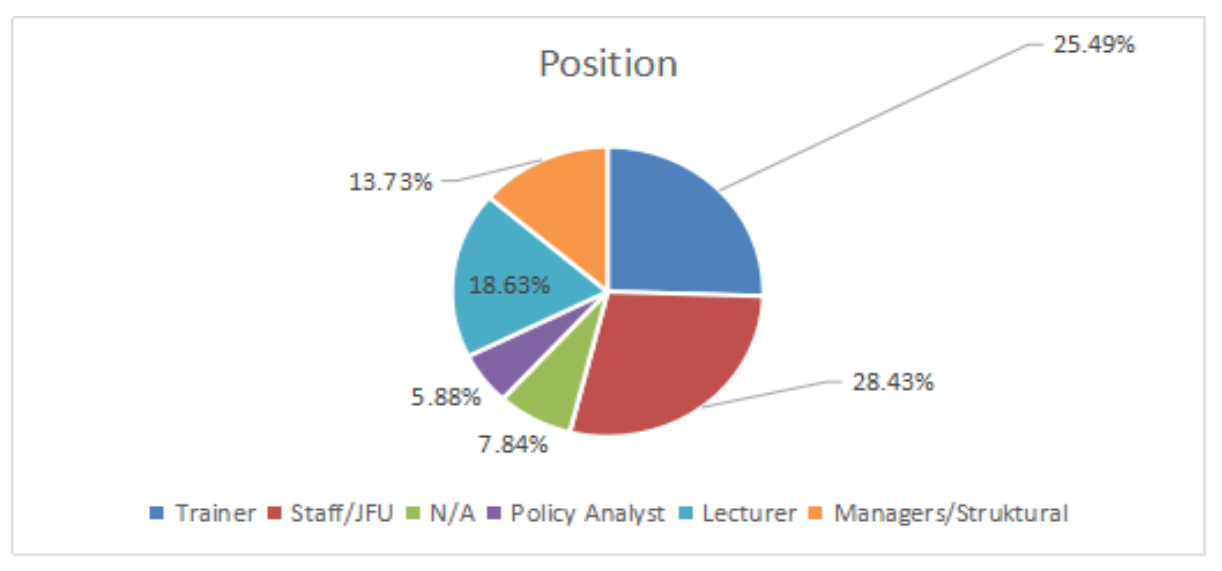

Figure 1: Breakdown of respondents' work role

The proportion of teacher/trainers involved in the survey reflects the representation of this group across NIPA responsibility of $26.43 \%$ (Sacks \& Pierskalla, 2018), but the other job classifications are not as well represented within the NIPA cohort. However, it should be noted that almost $8 \%$ of our sample chose not to declare their position, which could affect these proportions.

In this paper we have aimed to examine the perceived effectiveness of human capability development training occurring within NIPA across the five Indonesian employment contexts mentioned earlier. This research occurred in the middle of the COVID-19 pandemic and has implications for practitioners as they have designed and developed human capability development programs for implementation in Indonesia in the post COVID-19 context. The Indonesian bureaucratic structure, with respect to the size of the ministries and the culture within particular ministries, impacts on the ability to make any significant inroads into human capability development in the Archipelago. This important task falls into the hands of the NIPA (Murti, 2020), and to add detail to this study, Table 1 provides a profile of the respondents by educational background.

Table 1: Breakdown of respondents by educational background

\begin{tabular}{|l|l|l|l|}
\hline Code & Information & Total & $\%$ \\
\hline 1 & Doctoral & 9 & $9 \%$ \\
\hline 2 & Masters & 56 & $55 \%$ \\
\hline 3 & Bachelor & 25 & $24 \%$ \\
\hline 4 & Diploma & 12 & $12 \%$ \\
\hline & & 102 & $100 \%$ \\
\hline
\end{tabular}


The educational background of the respondents was considered relevant, as noted by Sacks and Pierskalla (2018), since those with post-graduate qualifications are more likely to be promoted and advance to more senior positions within the Indonesia Civil Service. Approximately $64 \%$ of the respondents to our study held post-graduate qualifications and we suggest that this would represent an 'upwardly mobile' cohort with significant potential for future advancement.

\section{The Indonesian Online Learning Experience}

There has been a rapid and dramatic shift toward e-learning across all educational environments, which include secondary and tertiary education, together with government training centres in Indonesia. A recent study by Tinungki and Nurwahyu (2020) has revealed that the Government of Indonesia's direction to secondary schools to use the 'Google classroom' for the delivery of the national curriculum during the COVID 19 pandemic, has exceeded expectations. These authors state that "the process standards and content standards of the implementation of education based on the National Education Standards and Standards of the relevant tertiary institution, have been fulfilled (76.3\%)" (Tinungki \& Nurwahyu, 2020). However, it is of concern that this optimistic assessment of educational achievement does not correlate with the respondent's perspectives from this study, as more than half of the respondents commented on the need to improve the learning management system and to upgrade the learning materials. In addition, independent media reports indicate that there is a growing disparity between classes within Indonesia in terms of their ability to access 'online learning'(Mulyanto, 2021 February 02). Supporting this latter view, Lestiyanawati (2020) noted, in a recent study of Indonesian teaching approaches online, that students from disadvantaged family backgrounds and with little parental support were significantly disadvantaged during the period of online teaching during COVID-19. The Government of Indonesia's 'measures of success' (Tinungki \& Nurwahyu, 2020) of online delivery should be considered in relation to the levels of digital inequality, where many disadvantaged families have to borrow smartphones, or have no tablets or laptops capable of accessing the internet. This disadvantage includes not having the resources to purchase data, and is exacerbated because some parts of Indonesia are without internet coverage.

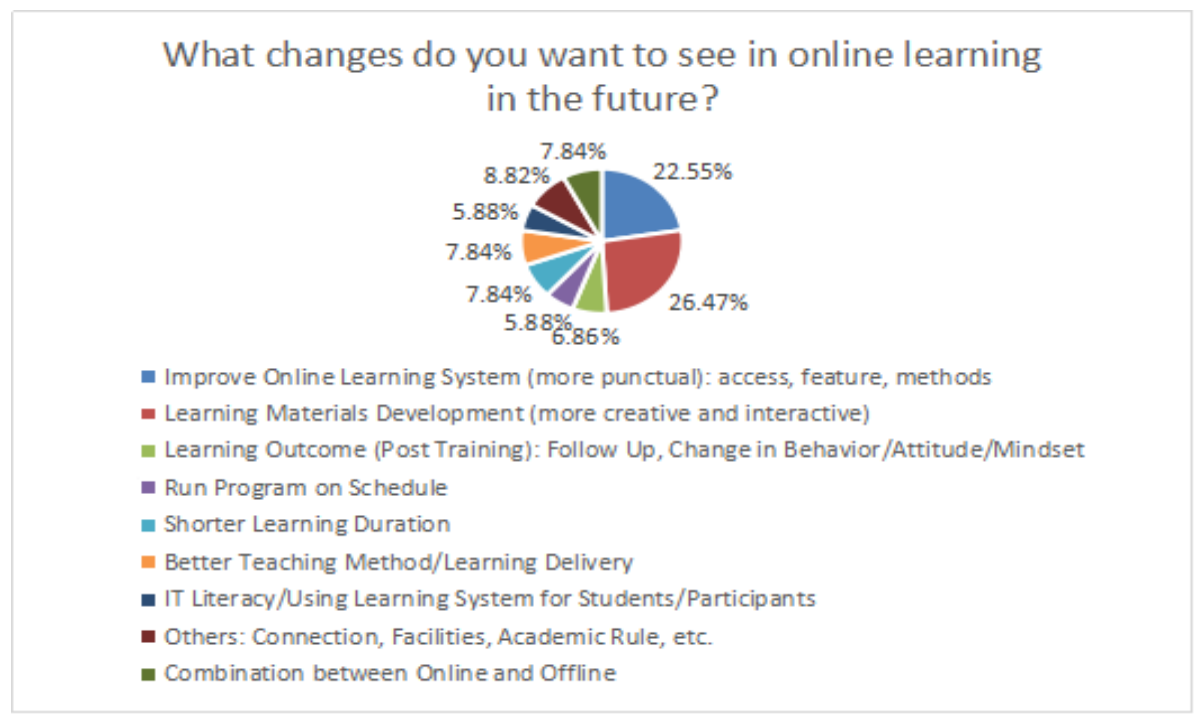

Figure 2: Respondents'suggestions for improving online education 
The shift toward online learning has highlighted the challenges commonly faced in classical training, and this has been illustrated by the research data which has suggested attempts which might establish positive outcomes for learning and post-training follow up. One common item was the conduct of follow-up post-training sessions to determine whether there has been any change in behavior, attitude and mindset in recent years. This issue was highlighted by $7.84 \%$ of the respondents and it concurs with the literature on evaluation of training; most notably from the seminal works of Kirkpatrick in Evaluating Training Programs (Kirkpatrick, 1993).

Many of the respondents commented on the difficulty of maintaining their focus and interest in the learning material during online learning, and have suggested a number of strategies that could be employed to maintain their motivation. These suggestions included; (i) chunking learning sessions into shorter time intervals, (ii) producing more creative and interactive sessions, and (iii) applying more appropriate teaching methods.

Table 2: Suggestions for increased motivation for learners

\begin{tabular}{|l|l|l|l|}
\hline No & Information & Total & $\%$ \\
\hline 1 & Competent Trainers & 26 & $23 \%$ \\
\hline 2 & Self- Motivation & 39 & $35 \%$ \\
\hline 3 & Professional Training Organizer & 5 & $4 \%$ \\
\hline 4 & Learning Materials: Modules, Assignments, etc. & 22 & $19 \%$ \\
\hline 5 & Environment Support: Family, Superior, Peers & 6 & $5 \%$ \\
\hline 6 & Ease Access of Learning System & 11 & $10 \%$ \\
\hline 7 & Others: Connection, Flexible Time, Facilities & 5 & $4 \%$ \\
\hline & & 114 & 100 \\
\hline
\end{tabular}

Many survey respondents commented on the importance of having 'competent trainers'. They were somewhat critical of the older traditional forms of learning, using PowerPoint and relying on facilitator-led instruction during this rapid move toward online learning, and similar comments are noted in studies at the higher education sector in Indonesia (Rahayu, 2019). This seems to perpetuate the previously dominant educational methodology within the educational landscape in Indonesia, known informally as 'guru centered' teaching. Some respondents commented on the need to have an 'emotional engagement' with the teacher/trainer, as they thought this might bring about better educational outcomes. One respondent described this by saying: "the emotional engagement online is less engaging, [and] this affects the level of learning", and another commented that "solutions to improve emotional rapport among participants are needed". Not all respondents were concerned with the 'emotional engagement', but were more interested in emphasizing the flexibility that the online learning method provided:

"I like the flexibility of online learning as I can review any time after the session. Especially when there is another activity at the office, I can come back to the online session in the evening. I prefer the blended one: online and classical."

An important finding was that, during a number of focus group discussions, participants noted the importance of achieving a balance between 'online' and 'classical' training approaches. Comments often reflected the need to mediate more deliberately between the two forms of training. In this 
respect, Otter et al. noted that 'students expressed a strong preference for class discussions to be conducted face-to-face, reporting that they felt more engaged, and received more immediate feedback, than in online discussion' (Otter et al., 2013). Classical training sessions provided opportunities to engage with the content and interact with both the trainer and the other participants. Comments such as "I prefer classical sessions - I can have a free discussion both with the trainer and fellow trainees" suggesting that methods for engaging with other participants were lacking in the online learning space. In addition, it was opined that "online learning is designed to help us learn, but the methods were not optimal. I prefer offline learning”.

In the responses to our questioning, participants indicated that improving the online learning experience was essential. This focus featured prominently, and some respondents went so far as to suggest that, perhaps at some time in the future, we will discover ways to have a "more personal and emotional engagement and collaboration using online technologies". Notwithstanding these strong comments, we noted that the issue of increasing 'rapport' and engagement was not completely shared across the cohort, as one respondent commented that "online learning can build rapport between trainers and participants", again highlighting the importance of mutual engagement with learners, but this time indicating that this could occur irrespective of the medium employed.

The technical issues of delivering learning programs online occasioned some comment, with one respondent noting "I found internet connection was a big issue, I got frequently disconnected during the learning". However, when communications went smoothly, a number of respondents commented that the e-Learning approach suited the Indonesian cultural approach to learning. The information was presented in a 'teacher centred' mode, and students simply had to 'Duduk dan Dengar' (Sit and Listen) (Carolan, 2005). In this latter respect, Al-Abri et al. (2017) noted that e-Learning delivery approaches re-enforced the teacher centered mode of learning as a consequence of using PowerPoints and one-way Lectures rather than more collaborative approaches (Al-Abri et al., 2017) Whilst many respondents deemed this to be a culturally relevant approach, it was also clear that there is a growing notion that this has led to a noticeable restriction in learner engagement, and thus an explicit perpetuation of teacher-centred pedagogy (Fairman, 2018). One focus group participant described this most eloquently:

"With the online learning, the ready-made materials are provided. The trainer prepared the recordings of his presentation. So we, 30 participants, learn passively relying merely on those available online. We just listen to the recordings without being able to present any questions, let alone to explore the issue under discussion."

It was noted in our survey that it was apparent amongst the cohort that the onus was on the individual to maintain their motivation during the online learning sessions. One response was that: "with the online learning I could freely determine when I want to learn and how much I want to learn". Indeed, more than a third of the respondents commented that self-motivation was critical to successful online engagement. Of importance here was that many of the respondents were working from home during the conduct of this survey, and there were many domestic distractions. It was clear that issues related to family life significantly impacted upon their ability to maintain motivation. This issue of managing time between work and family creates a paradox in that it is likely to mean having less communication with family members yet spending more time at home. 


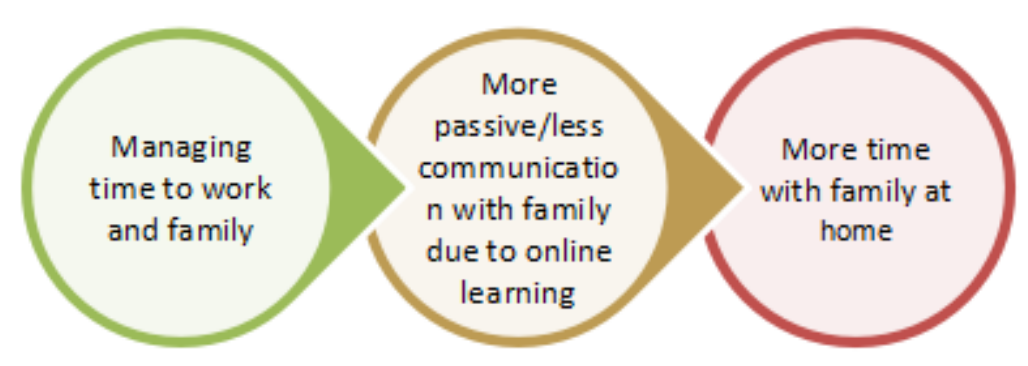

Figure 3: Work-Home life impacts

Because the nature of interactions between work and family was significantly impacted by the move to 'working' from home, this strain was reflected in the responses to the benefits or otherwise of online learning. Whilst there were clearly perceived benefits of working from home because of having less travel time and therefore having more time at home with the family, it was not uniformly agreed that working from home was totally positive. The added time at home was perceived as fostering 'passive' communication between family members, whilst at the same time adding to the stress rising from the need to concentrate fully on the online learning material.

With these reflections in mind, we see that some important questions emerge. These include: (i) To what extent does 'online learning' suit traditional ways of learning in Indonesia? (ii) What learning cultures are perpetuated through 'online' learning? (iii) How do we address the problem of bandwidth and data sharing across the Archipelago? (iv) What impact is e-learning having on NIPA staff and how is this managed? (v) What is the impact on the Indonesian civil service with this rapid expansion of e-Learning? This paper further explores these issues through the responses of civil service practitioners. 


\section{Institutional Support}

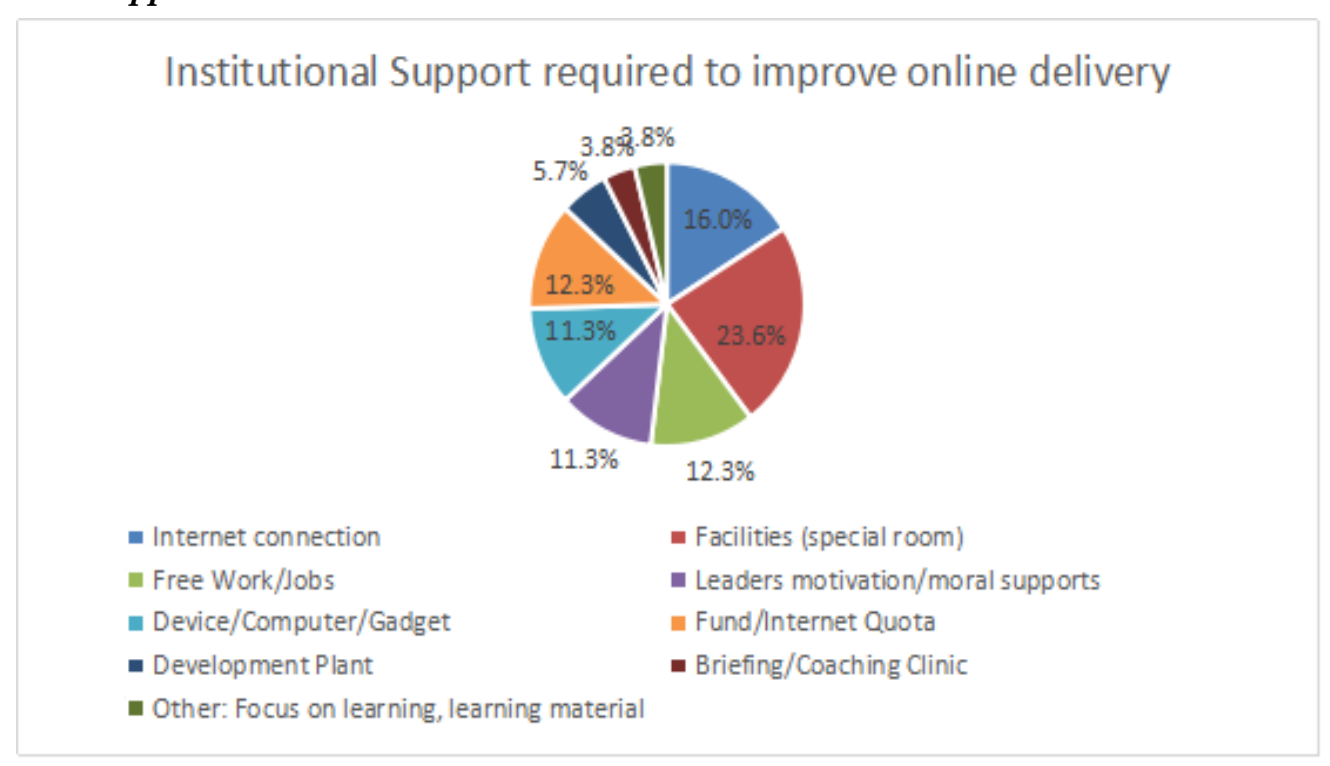

Figure 4: Institutional support required for online training

\section{Online Learning at Work}

The most notable challenge experienced by our respondents was the disturbance from work colleagues during online classes. Many Indonesian work environments have "shared office' spaces, which are not conducive to focused learning. To reduce this strain, Employers and Institutions need to provide dedicated 'learning spaces' for online learning. This was illustrated by the comment: "[It is essential that] quality of internet connection and supportive stable power and a learning room with required standards of lighting and free from external noise [is provided]". In addition to better facilities, many respondents commented on the lack of appropriate hardware and poor internet connectivity. This was possibly due to the number of fellow colleagues accessing the internet at the same time. A common comment was that "Improving internet capacity at the office and updating supporting devices, such as laptops or computers with the required specifications" are required.

Overwhelmingly, respondents commented that institutions should "provide [adequate] support facilities and infrastructure for online learning". The support referred to includes dedicated training rooms, online resources, technical support and facilities, together with hardware such as properly equipped computers and laptops. It is nevertheless agreed that there were many benefits associated with working from the workplace, including stronger and more stable Internet connectivity, being able to include and interact with work colleagues whilst online, and having easier access to learning resources.

Table 3: Factors that hindered online learning

\begin{tabular}{|l|l|l|l|}
\hline No & Information & Total & $\%$ \\
\hline 1 & Unstable internet connections & 54 & $53 \%$ \\
\hline 2 & Online Assignment & 9 & $9 \%$ \\
\hline 3 & Learning New Methods & 4 & $4 \%$ \\
\hline 4 & Time Management: Learning Versus Office Works & 7 & $7 \%$ \\
\hline
\end{tabular}




\begin{tabular}{|l|l|l|l|}
\hline 5 & Long Duration Make Tired/Fatigue & 13 & $12 \%$ \\
\hline 6 & Personal Motivation: Emotion, Focus, Concentration & 9 & $9 \%$ \\
\hline 7 & Environment constraint at home & 4 & $4 \%$ \\
\hline 8 & Others: System Complicated, Improve Competency & 2 & $2 \%$ \\
\hline & & 102 & \\
\hline
\end{tabular}

It was widely agreed that the lack of existence of a quality Internet service provision seriously hampers any attempts to move toward online learning in Indonesia. Invariably, when questioned about the quality of the online training, respondents' concerns were focused on poor Internet service, disruption and connectivity, all of which were exacerbated by uneven power supplies. These challenges and issues were identified whether working from home, or in the workplace. Unstable Internet connection was deemed to be the major factor in hindering online learning, but, that said, whilst resolving the 'connectivity' issues would be a significant improvement, this would not resolve a number of environmental issues, lack of personal motivation, poor time management strategies and the need to learn how to address new learning methods. Indeed, it is apparent that there is a need to address issues of 'focus, concentration, and motivation' which arise from work fatigue. One respondent describes the dilemma of working from home, suggesting that "it really needs a big commitment, requiring a time commitment and little disturbance like signal (internet connection failures)" and concluded by saying that "classic learning is better than online learning as there is more engagement and [opportunities for] creativity". This view, however, was not uniformly held by all respondents, with one respondent, who had had positive previous experiences with e-learning, describing their position on this question as "for me learning online was fun, challenging and unique".

\section{Learning Approaches}

Whilst the COVID pandemic has hastened the acceptance of learning in a digital context, tertiary institutes in Indonesia have struggled with this paradigm shift (Rahayu, 2019). While NIPA was preparing for a greater role for e-learning in their teaching structure and had provided a framework and regulations to support this in 2018 , they were caught by the rapidity of the change. One comment was that "we thought it was [going to be] 4-5 years in the future, however BANG, and it's here now". It was noted that, not unexpectedly this rapid move to online learning suited younger people more familiar with social media and digital technology than older employees. Older employees were illequipped to deal with the rapid change into e-learning (Lestiyanawati, 2020), and they strongly expressed the need for more staff development around using these new communication technologies such as Zoom, Google classroom and particularly Moodle, in order to develop more interactive learning tasks. This cohort suggested that on-line learning platforms need to respond to the perceived view by some researchers that students in an online learning environment are assumed to be more predisposed toward self-directed studies (Kemp \& Grieve, 2014). This may not be a universal case, and as such more creative and interactive learning methods may be urgently required to improve overall online learning experiences.

In the current manifestation of online learning, trainers and facilitators are expected to use generic learning management systems such as Moodle and Google classroom. However, it has been commented that the usability and the formative nature of these systems have a significant influence on the quality of e-learning (Seta et al., 2020). We have noted previously that this has caused 
considerable angst with some training staff, and certainly remains a professional development issue. Some respondents commented that they found the quality and transparency of support programs wanting, and in consequence they needed more intensive coaching and mentoring. In addition, they required more time to become familiar with these newer online forms of training delivery before being ready to use them with learners. In order to deliver comprehensive online courses, facilitators are required to develop complex lesson plan designs, supported by appropriate teaching materials such as audio and video content and technological support (Siron et al., 2020). The difficulty of doing this may explain why many of our respondents commented that staff "reverted to their 'old' ways of delivering training using 'PowerPoint's and Lectures”.

The Indonesian training context promotes a culture of 'inclusion', where participants on training are given a 'lanyard' upon entering the training room signifying that the person was 'in training', and this was only removed upon completion of training (Fairman, 2018). When NIPA conducts 'classical' training, this protocol is strictly adhered to, but in the 'online' training, this inclusive action is absent. The impact was noticeable in that respondents felt that whilst engaged in online training at work, other 'work tasks' interfered with their learning because they were not recognized as being in a special learning state. This situation of interruption whilst learning is certainly not so prevalent in 'classical' training, where the lecturer and lanyard are visibly present. In addition, the wearing of the lanyard created an equality of environment, where training participants were 'free to explore' ideas within the training room, irrespective of their 'job title' and 'external status'. This was an important notion that arose during this survey, highlighting the distinction between 'individualist and goal oriented' teaching versus 'respectfulness and inclusive' learning, which severely impacts upon the learning process, and openly challenges western concepts of adult learning (Fairman et al., 2020).

\section{Improvements required for online learning}

It was noted in the survey that an overwhelming $94 \%$ of respondents, felt 'less confident' in their work after undertaking 'online learning'. This feeling of being daunted by the technological expectations of online study (Kemp \& Grieve, 2014) is not uncommon, which means that uncovering the reasons behind such a high percentage of uncertainty is critical for improving the learning experience. With many of respondents suggesting that e-learning faced a number of barriers in Indonesia including internet access, internet connection speed and reliability, has led to a perception that it this mode of learning is less focused. However, making the most out of the existing online learning environment may be as simple as altering or varying facilitation strategies to allow learners in the online environment to engage in discussions with fellow learners, a practice which they claim to prefer. This accords with the findings of Otter et al. (2013), who suggested there is a need to structure classes in a manner that serves as an enabler for learning flexibility. This could be assisted by designing sessions which involve greater engagement experiences through simulated face-to-face discussion (Otter et al., 2013). For example, using learning platforms that facilitate 'breakout rooms' are essential to allow the students to work on smaller, and more intimate, group-work tasks. However, one respondent recognized it is also important for those facilitating such activities to ensure that appropriate time be allocated for all students to have an opportunity to raise issues and participate in a free discussion, both with the trainer and fellow trainees.

Researchers have expressed the view that online course developers should create greater engagement by designing environments where greater face-to-face interaction is an integral part of the learning 
session (Kemp \& Grieve, 2014). These purposively structured 'information flows' and 'discussions' play a central role in improving the online learning experience. Mitsakis and Karageorgakis (2020) posit that e-learning can potentially offer a more learner-centric experience through multiple-formed content by matching individual learning desires with media richness. Participants of our study certainly resonated with this view, agreeing that the e-learning experience would be enhanced by greater interaction between trainer and learners. This occurs naturally in the 'classical' classroom and thus should be a feature of the online experience. Other suggestions included providing more visual communication in the form of applications and features on mobile technologies. Limiting teacher-led instruction to an appropriate length of time was strongly suggested, noting that students cannot remain meaningfully engaged in a 50 minute lecture-style presentation unless this session is interspersed with items characteristic of 'student centered' pedagogies (Bunce et al., 2010).

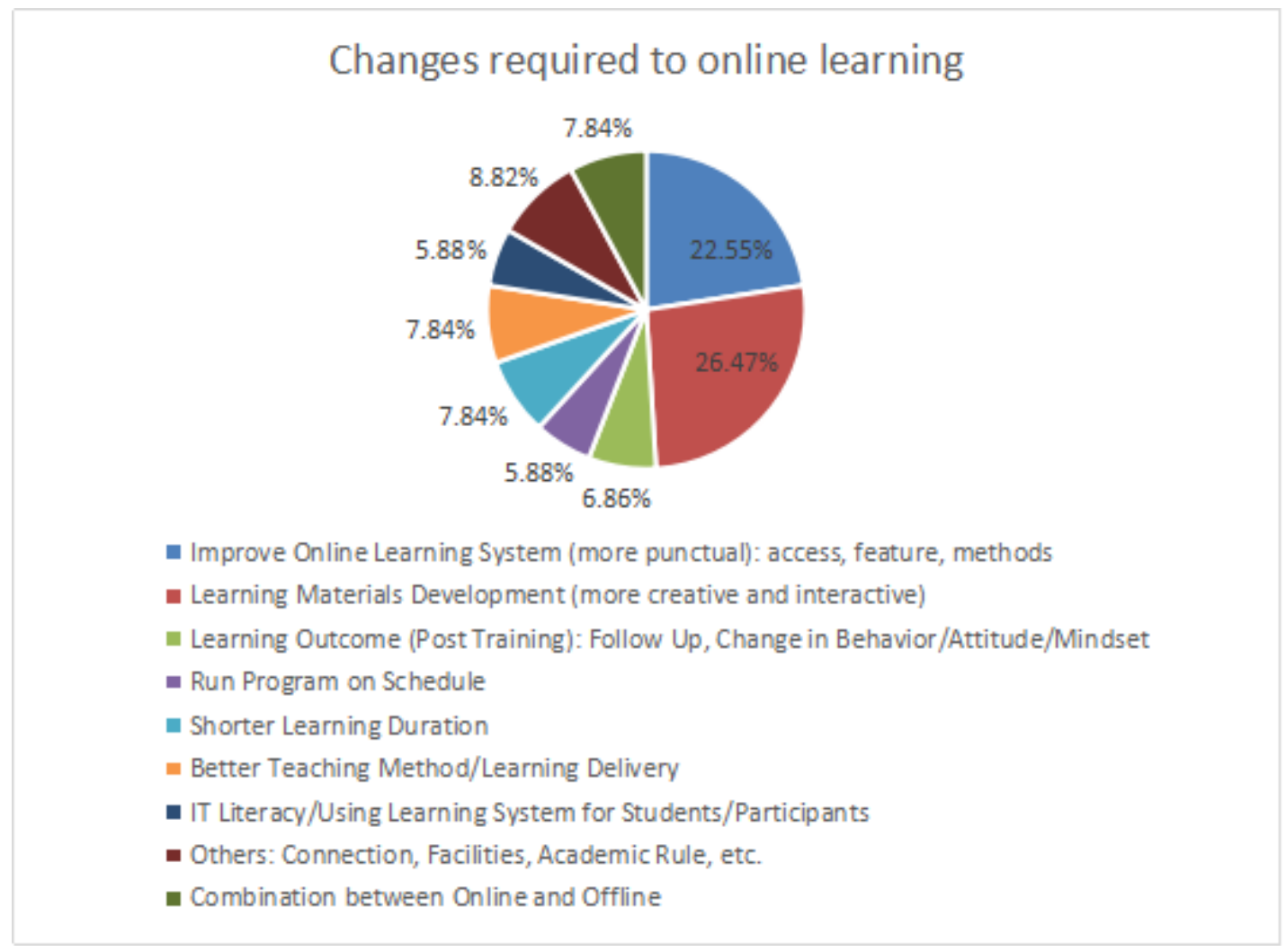

Figure 5: Improvements required for online delivery

Developing a 'student-centred' approach to learning involves incorporating learning activities which create active engagement. In this way, learners will be more participatory and engaging actors in the whole process of their training. A crucial factor in this regard is the design of human capability programs that have practical experiences which directly relate to, or mirror, an actual work environment. For the Indonesian Civil Service, the involvement of civil society, government and/or business issues are critical to the success of these practical learning experiences.

\section{Closing Remarks}

This study has revealed that NIPA's rapid and dramatic shift to e-learning has significantly challenged conventional or 'classical' learning delivery strategies across human capability development programs within the Indonesian Civil Service. Whilst there may be significant 'budgetary and cost' benefits to 
conducting e-learning, there remains question around its 'effectiveness' in providing structured development for NIPA trainers and facilitators in order to improve e-learning delivery quality, Further, NIPA needs to examine strategies to better utilize the advantages of "communities of practice' in order to enhance the performance and skill of trainers outside the realms of NIPA influence.

Are we there yet? Whilst the journey perforce continues, the rapid and dramatic shift to e-learning has highlighted the importance of 'equity' in human capability development programs. Further research is necessary to determine whether the existing training and facilitator professional development programs are addressing the future needs of NIPA. Investigation is needed into the equipping of training staff with the skills to deliver e-learning programs, the management of learning management systems and the complementary design and IT capabilities appropriate to create innovative and engaging online content. This current study has highlighted some concerns experienced by NIPA training recipients, suggesting that further assessment of training interventions might prove beneficial. Overwhelmingly, e-learners reflected their perspective of a need for a learning environment that mirrors 'classical' training. This development would require competent and skilled facilitators with an 'understanding' of the complexities and limitations of e-learning platforms. We believe that further research questions could examine:

- What personal and institutional changes are required to improve current e-learning experiences?

- What professional development works best to improve the e-learning experience?

- How might 'communities of practice' be used to enhance e-learning delivery?

- To what extent can learners implement newly acquired knowledge and skills through an elearning experience?

Overall, what has emerged is that whilst there may be other equally important questions, learners nonetheless need to assess their role in capability development interventions, thereby positioning themselves to take more active responsibility for the learning process.

\section{References}

Al-Abri, A., Jamoussi, Y., Kraiem, N., \& Al-Khanjari, Z. (2017). Comprehensive classification of collaboration approaches in E-learning. Telematics and Informatics, 34(6), 878-893.

Bunce, D. M., Flens, E. A., \& Neiles, K. Y. (2010). How Long Can Students Pay Attention in Class? A Study of Student Attention Decline Using Clickers. Journal of Chemical Education, 87(12), 14381443. https://doi.org/10.1021/ed100409p

Carolan, C. (2005). Evaluation Report Certificate IV in Workplace Training and Assessment. Dili Institute of Technology.

Fairman, B. (2018). Looking for a way out: Skills development and training and its impact on aid practices and their development outcomes, with particular reference to Indonesia and Timor-Leste Victoria University].

Fairman, B., Voak, A., Abdullah, H., \& Indarjo, A. (2020). Re-skilling vocational education and training practitioners in Indonesia. Journal of Physics: Conference Series, 1516, 012045. https://doi.org/10.1088/1742-6596/1516/1/012045 
Kardinasari, R. (2015). Model uji kinerja dan kompetensi. Civil Service Journal, 9(1 Juni).

Kardinasari, R., Iskandar, T. Z., Nugraha, Y., \& Jatnika, R. (2019). Social Sensitivity Effect to Public Service Competence and Its Impact on the Head of Sub-district Performance in West Java Province. Psychology, 9(1), 22-31.

Kaunang, S. T. G., \& Usagawa, T. (2017). A New Approach for Delivering e-Learning Complex Courses in Indonesia. International Journal of e-Education, e-Business, e-Management e-Learning, 7(2), 132-145.

Kemp, N., \& Grieve, R. (2014). Face-to-face or face-to-screen? Undergraduates' opinions and test performance in classroom vs. online learning. Frontiers in psychology, 5, 1278. https://www.frontiersin.org/articles/10.3389/fpsyg.2014.01278/full

Kirkpatrick, D. (1993). Evaluating Training Programs. Berrett-Koehler.

Lestiyanawati, R. (2020). The Strategies and Problems Faced by Indonesian Teachers in Conducting e-learning during COVID-19 Outbreak. CLLIENT (Culture, Literature, Linguistics, English Teaching), 2(1), 71-82.

Mulyanto, R. (2021 February 02). Indonesia: Lessons from the online classroom. Retrieved April 25 2021 from https://www.aljazeera.com/news/2021/2/2/how-students-teachers-in-indonesia-cope-withonline-learning

Murti, F. P. (2020). Managing Training for Civil Servants with Planning Roles in Indonesia: Lessons from Singapore. Jurnal Perencanaan Pembangunan: The Indonesian Journal of Development Planning, 4(1), 76-102.

Otter, R. R., Seipel, S., Graeff, T., Alexander, B., Boraiko, C., Gray, J., . . . Sadler, K. (2013). Comparing student and faculty perceptions of online and traditional courses. The Internet and Higher Education, 19, 27-35.

Rahayu, M. K. P. (2019). Barriers to Use E-Learning Platform in Indonesia Higher Education: Factors Related to People and Organization. 2019 International Conference on Organizational Innovation (ICOI 19),

Sacks, A., \& Pierskalla, J. H. (2018). Mapping Indonesia’s Civil Service.

Seta, H. B., Hidayanto, A. N., \& Abidin, Z. (2020). Variables affecting E-learning services quality in indonesian higher education: students'perspectives. Journal of Information Technology Education, 19.

Siron, Y., Wibowo, A., \& Narmaditya, B. S. (2020). Factors affecting the adoption of e-learning in Indonesia: Lesson from Covid-19. JOTSE: Journal of Technology and Science Education, 10(2), 282295.

Tinungki, G. M., \& Nurwahyu, B. (2020). The Implementation of Google Classroom as the ELearning Platform for Teaching Non-Parametric Statistics during COVID-19 Pandemic in Indonesia. 